\title{
Article \\ Selection of Vertiports Using K-Means Algorithm and Noise Analyses for Urban Air Mobility (UAM) in the Seoul Metropolitan Area
}

\author{
Junyoung Jeong ${ }^{1}$, Minjun So ${ }^{1}$ and Ho-Yon Hwang $1,2, *$ [D \\ 1 Department of Aerospace Engineering, Sejong University, 209, Neungdong-ro, Gwangjin-gu, \\ Seoul 05006, Korea; wjdwns0808@sju.ac.kr (J.J.); visionmj.1014@gmail.com (M.S.) \\ 2 Department of Convergence Engineering for Intelligent Drone, Sejong University, 209, Neungdong-ro, \\ Gwangjin-gu, Seoul 05006, Korea \\ * Correspondence: hyhwang@sejong.edu; Tel.: +82-10-6575-2282
}

Citation: Jeong, J.; So, M.; Hwang, H.-Y. Selection of Vertiports Using K-Means Algorithm and Noise Analyses for Urban Air Mobility (UAM) in the Seoul Metropolitan Area. Appl. Sci. 2021, 11, 5729. https://doi.org/10.3390/ app11125729

Academic Editor: Rosario Pecora

Received: 27 May 2021

Accepted: 18 June 2021

Published: 21 June 2021

Publisher's Note: MDPI stays neutral with regard to jurisdictional claims in published maps and institutional affiliations.

Copyright: (c) 2021 by the authors. Licensee MDPI, Basel, Switzerland. This article is an open access article distributed under the terms and conditions of the Creative Commons Attribution (CC BY) license (https:// creativecommons.org/licenses/by/ $4.0 /)$.

\begin{abstract}
In this study, a combination of well-established algorithms and real-world data was implemented for the forward-looking problem of future vertiport network design in a large metropolitan city. The locations of vertiports were selected to operate urban air mobility (UAM) in the Seoul metropolitan area based on the population of commuters, and a noise priority route was created to minimize the number of people affected by noise using Aviation Environmental Design Tool (AEDT) software. Demand data were analyzed using survey data from the commuting population and were marked on a map using MATLAB. To cluster the data, the K-means algorithm function built in MATLAB was used to select the center of the cluster as the location of the vertiports, and the accuracy and reliability of the clustering were evaluated using silhouette techniques. The locations of the selected vertiports were also identified using satellite image maps to ensure that the location of the selected vertiports were suitable for the actual vertiport location, and if the location was not appropriate, final vertiports were selected through the repositioning process. A helicopter model was then used to analyze the amount of noise reduction achieved by the noise priority route, which is the route between the selected K-UAM vertiports compared to the shortest distance route. As a result, it was shown that the noise priority route that minimized the amount of noise exposure was more efficient than the business priority routes.
\end{abstract}

Keywords: UAM; ODM; vertiport; eVTOL; K-means clustering; AEDT; noise analysis

\section{Introduction}

The metropolitan area of South Korea includes Seoul, Gyeonggi-do, and Incheon and accounts for $11.8 \%$ of the South Korean area. The population of the metropolitan area included over 26 million people in 2019, accounting for 50.03\% of the total population. Seoul occupies a small area of $605 \mathrm{~km}^{2}$ but has a population of 10 million people [1]. Seoul already has a saturated population, and economic losses due to traffic congestion continue to increase. In addition, demand for transportation is increasing due to the rapid construction of new cities around the metropolitan area. However, congestion costs are expected to increase, as traffic volume in some zones, especially during rush hour, exceeds the capacity due to the lack of transportation facilities. Also, the congested road zones in the metropolitan area are concentrated on the road connecting Seoul and Gyeonggi-do, which is $159.8 \mathrm{~km}$ long, as shown in Table 1. Accordingly, as of 2019, the average commuting time by public transportation in the Seoul metropolitan area was $81 \mathrm{~min}$ : 2.8 times higher than the OECD average of $29 \mathrm{~min}$ [2]. Therefore, to overcome this traffic issue, many companies are actively working on urban air mobility (UAM), i.e., air public transportation rather than ground. 
Table 1. Major congestion zones.

\begin{tabular}{|c|c|c|c|}
\hline Category & Road Type & Road Name (Section) & Extension (km) \\
\hline \multirow{3}{*}{$\begin{array}{l}\text { Rush hour } \\
\text { congestion }\end{array}$} & Highway & $\begin{array}{l}\text { Seoul outer ring expressway (Gyeyang } \\
\text { IC-Jungdong IC-Ahnhyun IC), west coast } \\
\text { expressway (Ansan JC-West Seoul TG), 2nd } \\
\text { Gyeongin expressway (Gwangmyeong } \\
\text { IC-Iljik JC), etc. }\end{array}$ & 75.3 \\
\hline & City express & $\begin{array}{c}\text { Gangbyeonbuk-ro (Seongsan Large } \\
\text { Bridge-Dongho Large Bridge), internal } \\
\text { beltway (Yeonhee IC-Hongjimun tunnel } \\
\text { entrance), Dongbu main road (Jungnang } \\
\text { Bridge-Wolgye Bridge), Olympic daero } \\
\text { (Gayang Large Bridge-Yeoui Downstream } \\
\text { IC), etc. }\end{array}$ & 84.5 \\
\hline & Total & & 159.8 \\
\hline
\end{tabular}

Although helicopters are commonly used in urban areas, helicopters are not suitable for UAM, such as air taxis, due to the noise, emissions, and high costs of operation. Thus, electric vertical take-off and landing (eVTOL) vehicles have emerged as an alternative. Many eVTOL vehicles are under development, such as Airbus Vahana, Cityairbus, Lilium Jet, Bell Nexus, Joby S4, Hyundai SA-1, etc., and Uber has announced Elevate, a project that will allow commuters to use flying cars by 2026 [3].

According to a UAM survey of major specific cities conducted by Booz Allen Hamilton, more than $50 \%$ of commuters responded positively to UAM boarding [4], and if UAM becomes commercialized, many commuters would use eVTOL when commuting. Therefore, the locations of the vertiports should be in a place that is conveniently accessible to commuters. UAM will minimize traffic congestion on ground roads, and it is believed that this change will be positive for most of the population.

In addition, we must consider that this is a new transportation method that has never existed before, so infrastructure is needed to support it. In other words, eVTOL should be designed not only for take-off and landing but also for service infrastructure, such as vertiports, which allow passengers to stand by and board. The problem of emissions and noise should also be considered because the air transport is being operated in urban areas. Moreover, in the case of the Seoul metropolitan area in South Korea, where the area of land is limited, and the residential area is excessively concentrated, these issues are exacerbated. In addition, since the noise level is relative to people, it is important to first analyze it with indicators of standard noise intensity and later create a sustainable system under mutually beneficial conditions for all stakeholders.

As UAM emerges as an alternative transportation in the near term, adverse energy and environmental impacts, particularly noise, may impact community acceptance and potentially persist as the market matures into larger-scale operations. Of the concerns raised, the potential for noise was one of the most commonly raised concerns. However, people were less concerned about individual aircraft noise and more concerned about total ambient noise from multiple aircraft operating in close proximity. People indicated a preference for limiting aircraft operations overnight, particularly in residential neighborhoods.

The most common bothersome noises experienced by the respondents were noise from motor vehicles and neighboring properties, and they tended to be most bothered by noise at home. Overall, respondents preferred that UAM technology have no noticeable noise. The noise levels of the technology could affect support for UAM.

Noise impacts are expected to be more severe near the take-off and landing areas. Existing noise concerns focus on traffic noise during the night and early morning; noise from UAM could pose a more notable obstacle in the future as electric vehicles become more mainstream (potentially causing a reduction in overall ambient noise, making UAM more noticeable) [4].

Design of transport network, whether land, sea, or air, is a complex problem spanning many disciplines that would also encounter many real-world issues. There are many 
barriers and challenges, such as noise, to operate UAM. The Booz Allen Hamilton report [4] explored market size and potential barriers to UAM by focusing on three potential markets-airport shuttle, air taxi, and air ambulance. The barriers and challenges were also stratified according to their applicability or potential mitigation through technology as well as market maturity. In an immature market, the technology challenges are high cost of service, weather conditions, high density operations, battery technology, and environmental impacts, particularly noise. On the other hand, the non-technology challenges are infrastructure constraints, competition, and public perception [4].

For the UAM study, key metrics from the perspective of operators (e.g., number of flights, potential revenue, and operating costs), passengers (e.g., number and distribution), non-flying public (e.g., flight patterns, potential noise impacts), and infrastructure providers (e.g., number, location, and capacity of vertiports) should be calculated and tracked. However, in this study, only vertiport location selection and noise analysis were performed without considering all these factors [4]. To select vertiport locations, Antcliff et al. [5] came up with the idea of using highway cloverleaf interchanges, coastlines, river barges, and private infrastructures as UAM ground infrastructure locations. Also, Corgan, who collaborated with Uber, selected sites for their design in the Dallas/Fort Worth area, which is a primary launch market for Uber Air because of its high commuting population between cities, the high demand of air shuttle, and its existing helicopter routes for navigation [6]. Daskilewicz et al. [7] used census data from San Francisco and Los Angeles to collect commuting locations and commuting time. Using this data, 10, 20, and 40 vertiport locations were selected, solving an integer program that maximizes potential time savings compared to driving. German et al. [8] conducted an eVTOL study for small package delivery and also formulated and solved the optimization formula for maximizing the package demand served. Therefore, they derived one to eight vertiports positions. Rajendran et al. [9] proposed an iterative constrained clustering algorithm with the multimodal transportation warm-start technique. Using NYC taxi records, 10 to 85 vertiport locations were suggested, including large facilities and small stops. Ploetner et al. [10] defined three different UAM networks with different numbers of vertiports in the Munich Metropolitan region. Each network has 24, 74, and 130 vertiports, representing low, medium, and highdensity networks. Syed et al. [11] selected 200, 300, 400, and 1000 vertiport locations in Northern California using the K-means algorithm. Lim et al. [12] selected 10 to 36 vertiport locations using data from a survey from the commuting population and the K-means algorithm and selected three routes to analyze the savings in commuting time. For this study, however, data was filtered by adding assumptions that commuters would not commute to and from the same administrative district using the eVTOL, and vertiports were chosen based on the assumption of building a substantial number of vertiports required when the UAM is commercialized. In addition, regarding the issue of noise, Kim et al. [13] stated that eVTOL's noise is one of the most harmful effects of commercializing the technology, and the impact of noise on commuting using an eVTOL in San Francisco was analyzed through two scenarios of use for daily commuting. However, eVTOL noise data was not available in the Aviation Environmental Design Tool (AEDT), so it was modeled using four representative helicopters of different classes.

Uber established a subsidiary dedicated to UAM called Uber Elevate and led the market by standing out in eVTOL development and commercialization. It also plans to operate a certified vehicle in 2023 to generate revenue, signaling commercialization in Los Angeles, Dallas, and Melbourne, Australia. Regarding the selection of vertiports, the $\mathrm{K}$-means algorithm was used to select the most suitable places in LA and London, and in collaboration with Corgan, Uber announced the designs of vertiports in certain U.S. cities. In addition, various types of vertiports, such as parking lots, highway interchanges, and barges, were proposed to address difficulties in infrastructure design in urban areas [14]. However, Joby acquired Uber's UAM business in December 2020.

In this paper, the demand for eVTOL is analyzed by examining statistics of the number of people commuting, focusing on the Seoul metropolitan area in Korea, where $50 \%$ of 
the population lives. Vertiport locations are then selected for UAM using the commuter data and K-means algorithm. The Aviation Environmental Design Tool (AEDT), a software that analyzes environmental effects, such as noise, fuel consumption, emissions, and air pollution of aircraft, developed by the FAA (Federal Aviation Administration), was also used to perform noise analysis around the UAM route. In order to minimize the number of people affected by noise, the route was set in the form of noise priority rather than the shortest route directly connecting the origin to the destination. Finally, noise analysis was performed compared to the shortest route.

\section{Selection of Vertiports}

\subsection{UAM Demand Data Collection}

If UAM becomes commercialized, the commuting market is expected to be the most promising. To determine the demand for UAM for commuting, data were collected based on the current commuting population census conducted by Statistics Korea in 2015 [15]. The current residence and commuting administrative districts in the metropolitan area consist of 79 cities, counties, and districts. From the data, the number of the commuting population aged 12 or older in the metropolitan area is $14,335,975$. However, there is an assumption that commuters would not use UAM if their commuting area is the same administrative district as their residence, since it would not take much time in these cases. Based on this assumption, the population of commuters analyzed was reduced to 7,959,469. The administrative district with the largest population of commuters is Gangnam-gu, Seoul, with a total of 609,119 people commuting from other administrative districts.

To visualize the data obtained earlier, we used MATLAB to display it on the map, as shown in Figure 1 [16]. The K-means algorithm used in this paper requires the appropriate number of data for clustering so that the data allocated to each administrative area are rounded up and plotted on the map with one point per 5000 persons. The clustering process was repeated many times to obtain optimal locations of the vertiports. The shape of each administrative district was irregular, so it was assumed to be a square of the same size as the area of each district, as shown in Figure 2. Table 2 shows the number of commuters and data in the major administrative districts.

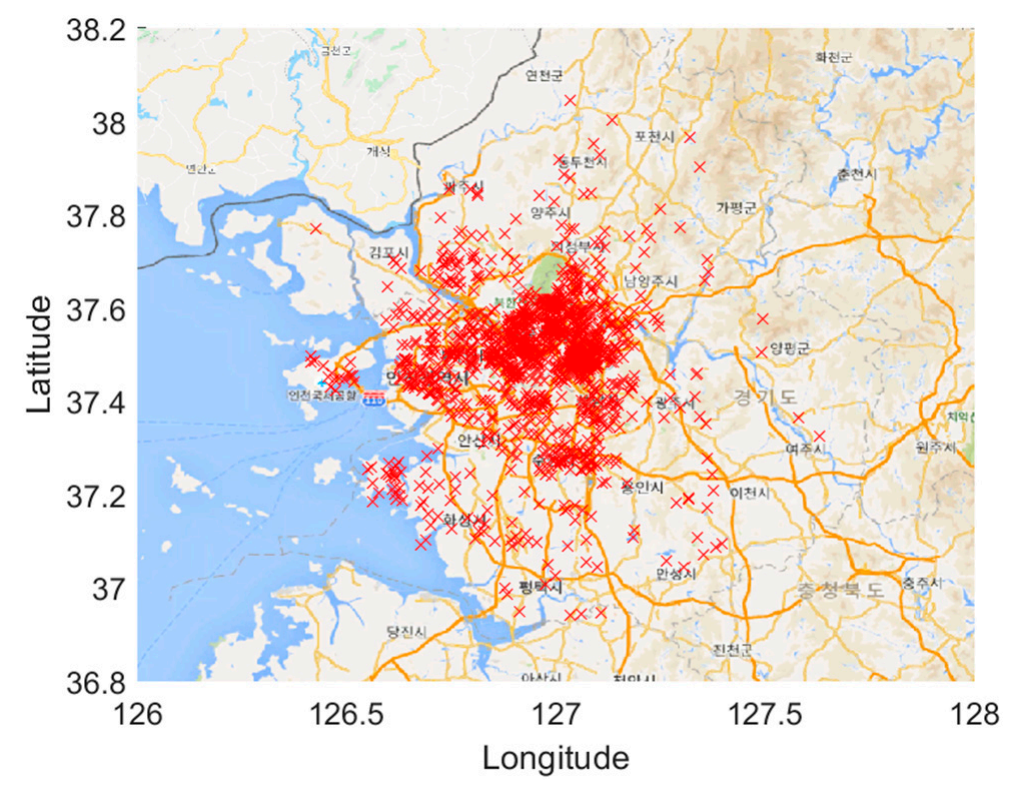

Figure 1. Commuter data expressed in MATLAB for each district. 


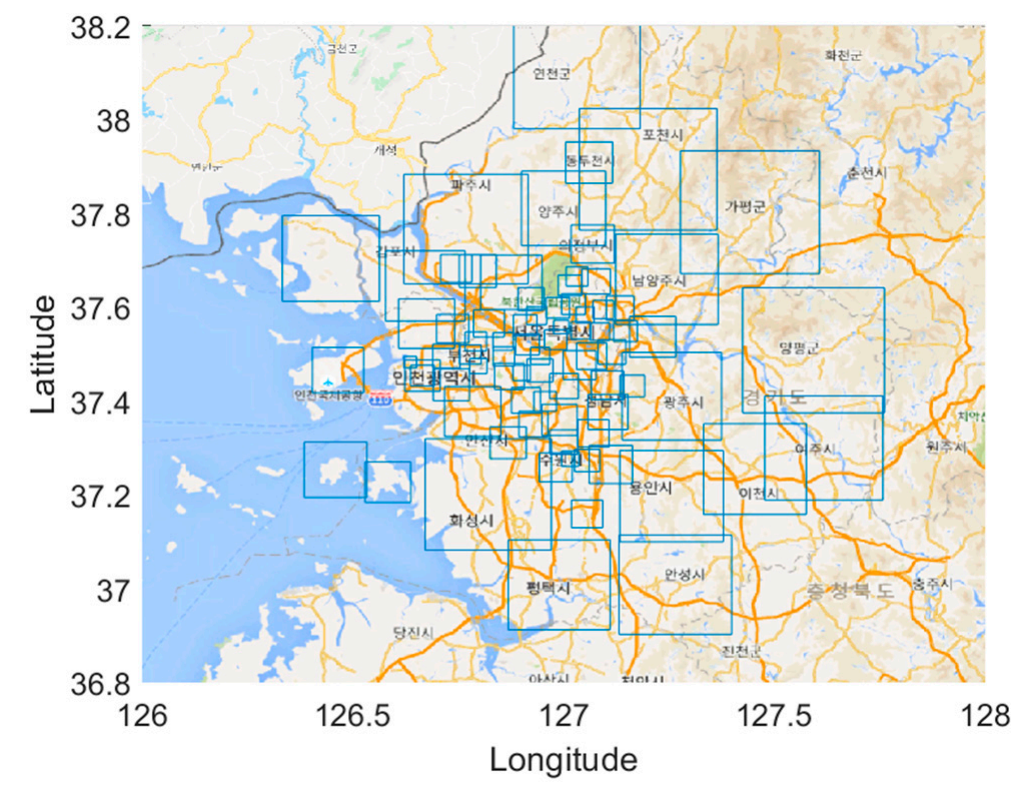

Figure 2. Administrative districts represented by squares.

Table 2. Number of commuters and data in major district.

\begin{tabular}{ccc}
\hline District & Number of Commuters & Number of Data \\
\hline Gangnam-gu & 609,119 & 122 \\
\hline Jung-gu & 352,261 & 70 \\
\hline Seocho-gu & 300,469 & 60 \\
\hline Jongno-gu & 282,783 & 57 \\
\hline Seongnam-si & 231,130 & 46 \\
\hline$\vdots$ & $\vdots$ & $\vdots$ \\
\hline Namdong-gu & 112,460 & 22 \\
\hline Total & $7,959,469$ & 1388 \\
\hline
\end{tabular}

\subsection{K-Means Algorithm}

The data collected earlier are the number of commuters in each administrative district, and this is closely related to the demand when the UAM is commercialized. Therefore, vertiports should be in appropriate locations to meet users' needs. For this purpose, the data was clustered using the MATLAB K-means algorithm. The K-means algorithm is most commonly used to cluster data into $k$ clusters. This minimizes the average squared Euclidean distance between the allocated data and the cluster center during the clustering process. The cluster center is defined as the mean or centroid $\mu$ of the data in a cluster $\omega$, as shown in Equation (1) [17].

$$
\vec{\mu}(\omega)=\frac{1}{|\omega|} \sum_{\vec{x} \in \omega} \vec{x}
$$

The measure of how well the centroids represent the data in their clusters is the residual sum of the squares or RSS, which is the squared distance of each vector from its centroid summed over all vectors, as shown in Equation (2). The objective of the K-means algorithm is to minimize the RSS.

$$
R S S=\sum_{k=1}^{K} \sum_{\vec{x} \in \omega_{k}}\left|\vec{x}-\vec{\mu}\left(\omega_{k}\right)\right|^{2}
$$


The most important thing in the K-means algorithm is that the parameter $k$ should be initially specified, and the entire process of clustering is repeated until the location of the cluster centers, where the data is allocated, remains unchanged. The iterative process can be simplified using the K-means function built in MATLAB, which represents the data earlier, but it is somewhat difficult to specify the $k$-value. As mentioned earlier, $k$ is the number of clusters and also the number of vertiports. In other words, the number of vertiports must be determined first, and the number is then used for clustering.

An arbitrary $k$ value can be assigned using a rule of thumb [18] to determine the approximate $k$ value for clustering or an elbow method to compare the results while increasing the number of $k$ values sequentially. However, according to Porsche Consulting in Germany, about 1050 eVTOLs are needed to replace various transportation types, such as private cars and public transportation for commuting in Sao Paulo, Brazil, which has 21 million people. In the case of vertiports, they announced they will initially start at existing transportation hubs, like airports and helipads. They initially planned five vertiports for 120 eVTOLs. They will then increase it to 40 and eventually to 100 vertiports [19]. Based on this information, it is assumed that 100 vertiports will be appropriate in the Seoul metropolitan area, which has a similar population to Sao Paulo.

How clustered data were formed when the $k$ value was 40 and 100 is presented in Figure 3. The data within the same cluster is presented as points of the same color, and the vertiports are symbolized as black stars.

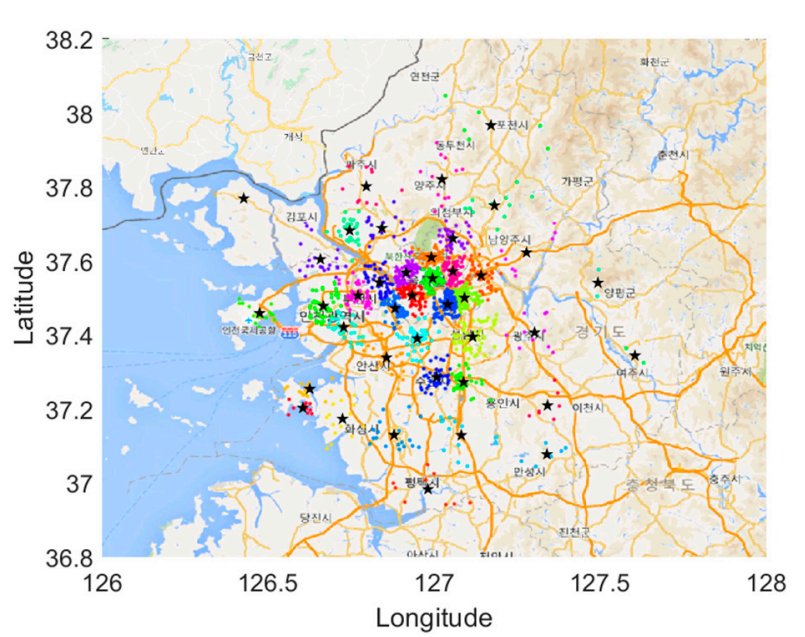

(a)

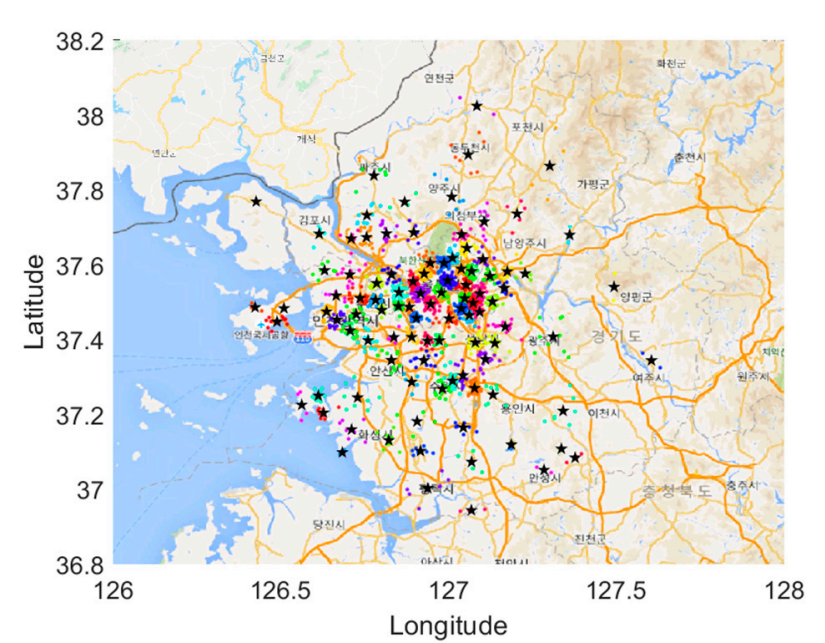

(b)

Figure 3. (a) Result of clustering when the number of vertiports is 40; (b) result of clustering when the number of vertiports is 100 .

There are various ways to build vertiport infrastructures in the Seoul metropolitan area; however, huge costs will be required since they will be located in urban areas. Therefore, it is very important to specify the exact number of vertiports, i.e., the parameter $k$.

\subsection{Silhouette Technique}

Since the K-means algorithm finally determines the centroid through an iterative process only when the $k$ parameter is specified, it creates critical limitations. Therefore, it is necessary to evaluate how well it is clustered with the specified $k$ value. The silhouette technique, which can evaluate by using a simple method among several evaluation methods, was used in this study. The silhouette technique was first proposed by Peter J. Rousseeuw in 1986 and is defined as follows. When the average distance between data $i$ 
and other data within the same cluster is $a(i)$, and the closest average distance between the data $i$ and other data in other clusters is $b(i), s(i)$ is [20]:

$$
s(i)=\frac{b(i)-a(i)}{\max \{a(i), b(i)\}},-1 \leq s(i) \leq 1
$$

The value of $s(i)$ is between -1 and 1 . The closer $s(i)$ is to 1 , the better the clustering, and the closer it is to -1 , the worse the clustering becomes. This process was performed using the silhouette function of MATLAB. The silhouette technique was performed for the two previous clustering results, and the results are shown in Figure 4. Each silhouette value of 1388 data points was grouped to represent a bar graph.

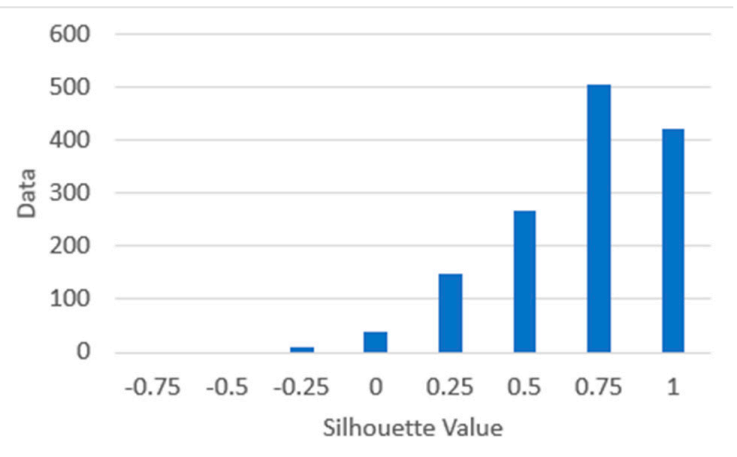

(a)

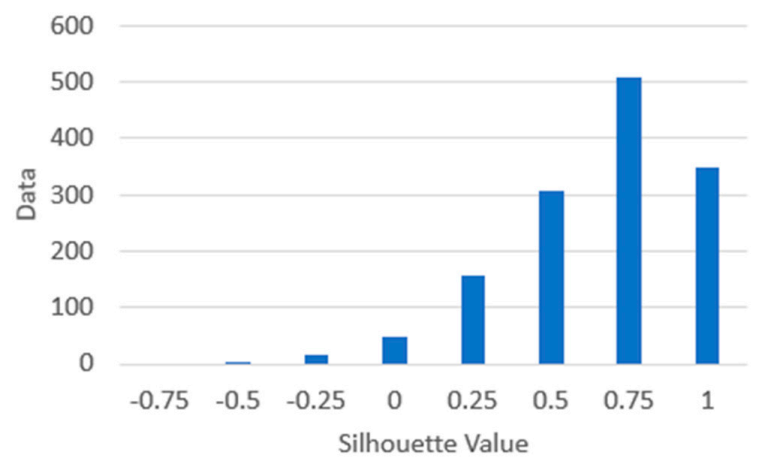

(b)

Figure 4. (a) Evaluation result of the silhouette technique when the number of vertiports is 40; (b) evaluation result of the silhouette technique when the number of vertiports is 100 .

The graph shows that the silhouette values of clustering 40 and 100 vertiports are closer to 1 , and averages are 0.5670 and 0.5291 , respectively. Therefore, we can conclude that clustering was successful.

\subsection{Vertiport Repositioning}

The location of the vertiport analyzed through clustering can be identified by latitude and longitude values, and those locations can be connected to create an operation path for the UAM. However, the final locations of the vertiports must be adjusted to reflect geographical conditions.

In the case of the Seoul metropolitan area, there are greenbelts designated as development restriction areas, as shown in Figure 5 [21], so vertiports cannot be built in those areas. Also, flight prohibition areas must be avoided for military reasons. In addition, in Seoul, where most of the population of South Korea resides, vertiports are likely to cause noise problems due to the operation of eVTOLs. Therefore, it is believed that highways, riversides, and creeksides will be the most suitable places for vertiports.

\subsubsection{Adjustments of Vertiport Locations}

After identifying the actual location of the clustered vertiport using the K-means algorithm, if it is not appropriate for a vertiport location, the clustering process can be repeated. An initial position is required in the K-means algorithm to initiate the iterative task for clustering; however, the K-means function in MATLAB arbitrarily sets its initial position. Therefore, it is possible to adjust the locations of vertiports just by retrying the clustering process. However, the appropriate site should be located around the centroid of the cluster presented in MATLAB and selected as the final location of the vertiport. Since the clustering results performed earlier represent the optimal latitude and longitude position through clustering retries, the locations of the final vertiports were selected by adjusting them to the appropriate sites near the centroid of the cluster in which the vertiport 
can be practically installed. In this process, the locations of all the selected and adjusted vertiports were identified using satellite image maps.

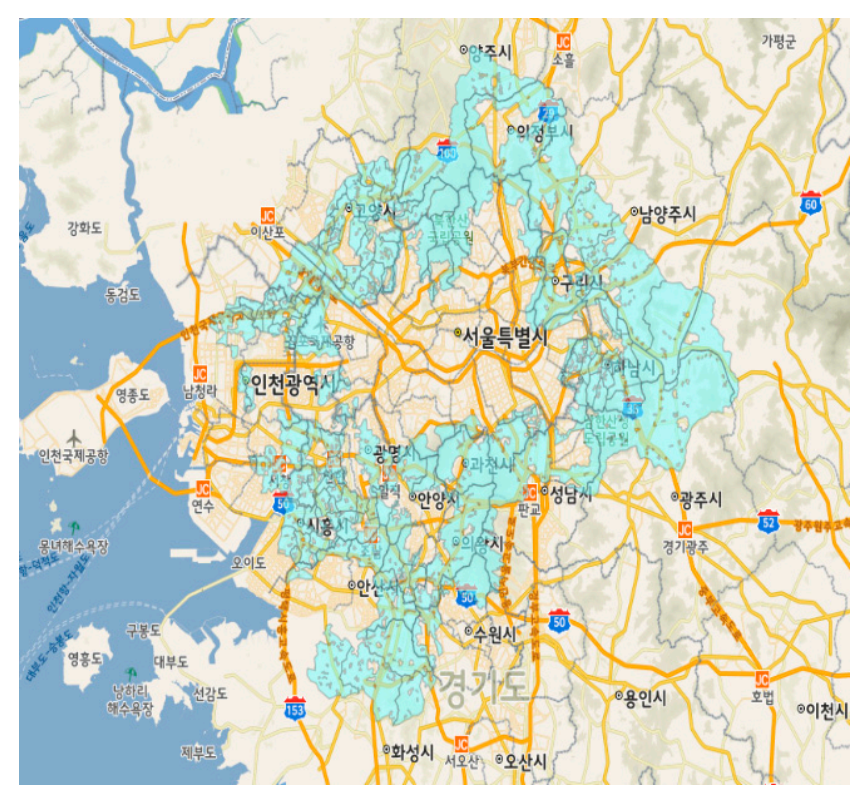

Figure 5. Seoul metropolitan area green belt.

\subsubsection{Forty Vertiports}

When clustered into 40 vertiports, the locations and administrative districts of each vertiport are shown in Table 3, and the locations of the final vertiports and their administrative districts are shown in Table 4 . The locations of the final vertiports are also represented in Figure 6.

Table 3. Location of vertiports when the number of vertiports is 40 .

\begin{tabular}{cccc}
\hline Number of Vertiports & Latitude & Longitude & Location \\
\hline 1 & 37.5066 & 126.9335 & Dongjak-gu \\
\hline 2 & 36.9834 & 126.9812 & Pyeongtaek-si \\
\hline 3 & 37.5607 & 127.1412 & Gangdong-gu \\
\hline$\vdots$ & $\vdots$ & $\vdots$ & $\vdots$ \\
\hline 38 & 37.8015 & 126.7957 & Paju-si \\
\hline 39 & 37.2096 & 127.3415 & Yongin-si \\
\hline 40 & 37.2029 & 126.6045 & Ansan-si \\
\hline
\end{tabular}

Table 4. Location of repositioned vertiports.

\begin{tabular}{cccc}
\hline Number of Vertiports & Latitude & Longitude & Location \\
\hline 1 & 37.5173 & 126.9399 & Yeongdeungpo-gu \\
\hline 2 & 36.9792 & 127.0773 & Pyeongtaek-si \\
\hline 3 & 37.5728 & 127.1669 & Gangdong-gu \\
\hline$\vdots$ & $\vdots$ & $\vdots$ & $\vdots$ \\
\hline 38 & 37.7446 & 126.7705 & Paju-si \\
\hline 39 & 37.2397 & 127.2934 & Yongin-si \\
\hline 40 & 37.2912 & 126.5776 & Ansan-si \\
\hline
\end{tabular}




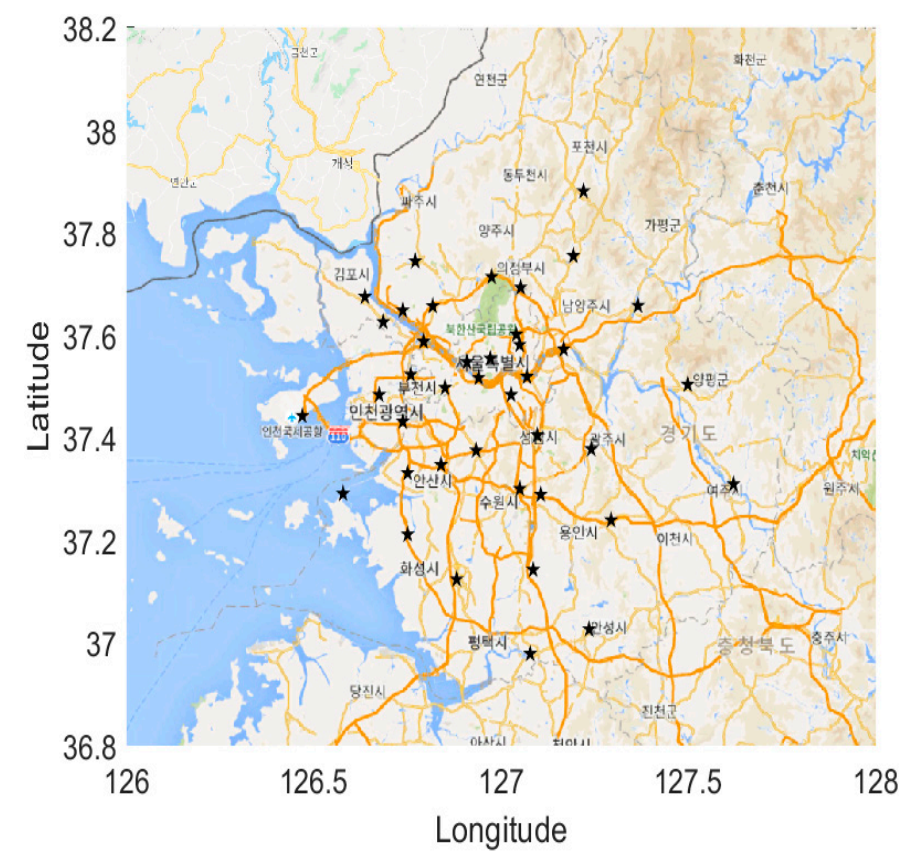

Figure 6. Location of repositioned vertiports.

\subsubsection{One-Hundred Vertiports}

When clustered into 100 vertiports, the locations and administrative districts of each vertiport are shown in Table 5, and the locations of the final vertiports and its administrative districts are shown in Table 6. The locations of the final vertiports are also represented in Figure 7.

Table 5. Location of vertiports when the number of vertiports is 100.

\begin{tabular}{cccc}
\hline Number of Vertiports & Latitude & Longitude & Location \\
\hline 1 & 37.5460 & 127.0520 & Seongdong-gu \\
\hline 2 & 37.2045 & 126.6271 & Ansan-si \\
\hline 3 & 37.5109 & 126.7360 & Bupyeong-gu \\
\hline$\vdots$ & $\vdots$ & $\vdots$ & $\vdots$ \\
\hline 98 & 37.0844 & 127.3771 & Anseong-si \\
\hline 99 & 37.4981 & 127.0734 & Gangnam-gu \\
\hline 100 & 37.4479 & 126.4885 & Jung-gu (Incheon) \\
\hline
\end{tabular}

Table 6. Location of repositioned vertiports.

\begin{tabular}{cccc}
\hline Number of Vertiports & Latitude & Longitude & Location \\
\hline 1 & 37.5421 & 127.0296 & Seongdong-gu \\
\hline 2 & 37.3315 & 126.7501 & Ansan-si \\
\hline 3 & 37.5234 & 126.7584 & Bupyeong-gu \\
\hline$\vdots$ & $\vdots$ & $\vdots$ & $\vdots$ \\
\hline 98 & 37.0921 & 127.4505 & Anseong-si \\
\hline 99 & 37.4943 & 127.0797 & Gangnam-gu \\
\hline 100 & 37.4579 & 126.4885 & Jung-gu (Incheon) \\
\hline
\end{tabular}




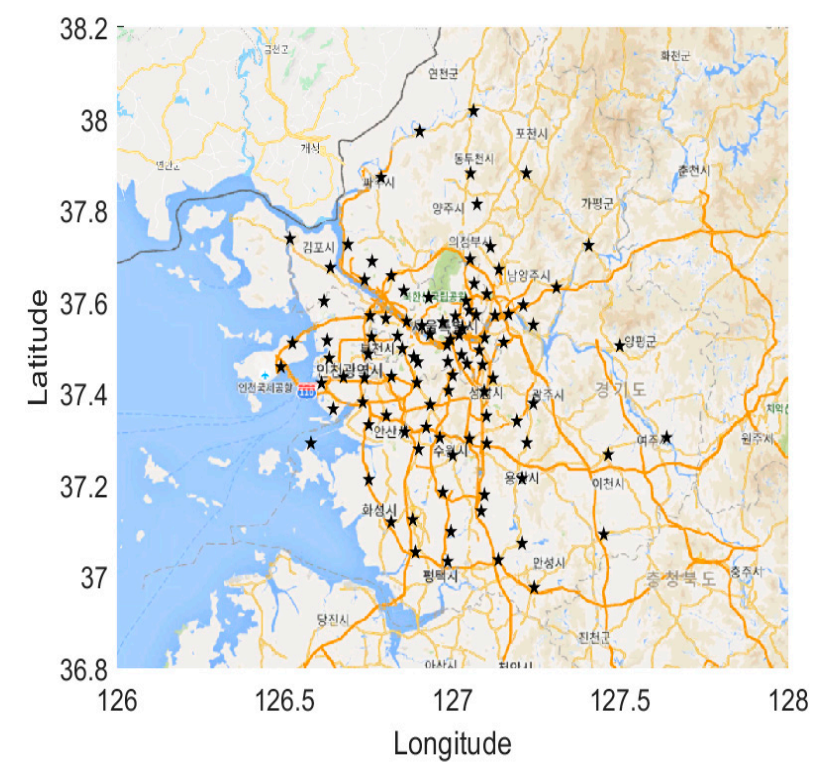

Figure 7. Location of repositioned vertiports.

\subsubsection{Final Vertiport Locations}

Examples of the adjusted final vertiports are shown in Figure 8. Most vertiports were selected near Han River Park or in cloverleaf highway interchanges (IC) in Gangnam$\mathrm{gu}$ and Seocho-gu. For fully populated residential areas, rooftop parking lots, such as Cheongnyangni Station in Dongdaemun-gu, or heliports in high-rise buildings were selected as vertiports. In addition, a vertiport was located at Gimpo Airport in Gangseo-gu to be used as an airport shuttle, the largest market for early UAM.
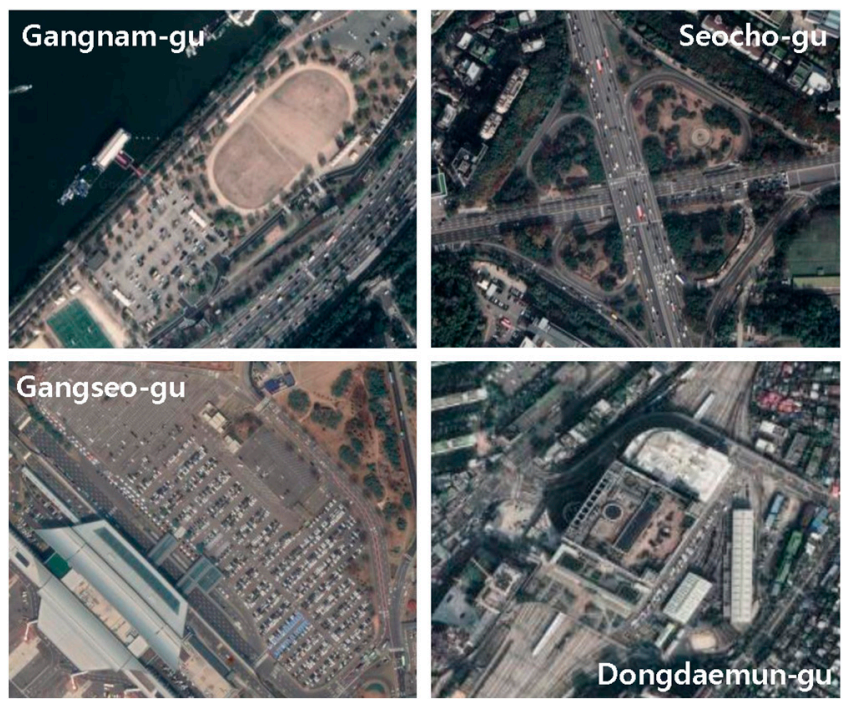

Figure 8. Examples of final 100 vertiports.

One of the input parameters required by the K-means algorithm is the number of clusters $(k)$, which is the number of vertiports. Due to the nature of the K-means algorithm, the location of the center of the cluster varies depending on the number of clusters. Therefore, a sensitivity analysis is needed to investigate how locations of the vertiports change for the changes of the parameter $k$. The locations of the vertiport when the number of vertiports is 10 and 40 are shown in Figure 9. Increasing the number of vertiports leads to an increase in passenger convenience by reducing distance and travel time from the departure point to vertiports and from vertiports to the final destination. However, if the $k$ value increases, the 
costs of building vertiports and operation will also be increased. In addition, the locations of the 10 vertiports are different from the 40 vertiport locations. Therefore, the optimal number of the vertiports should be determined before clustering is conducted.

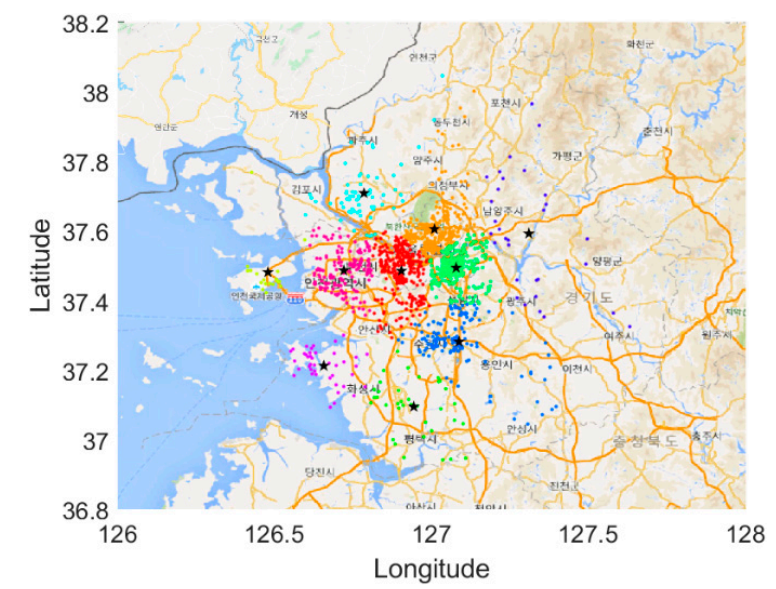

(a)

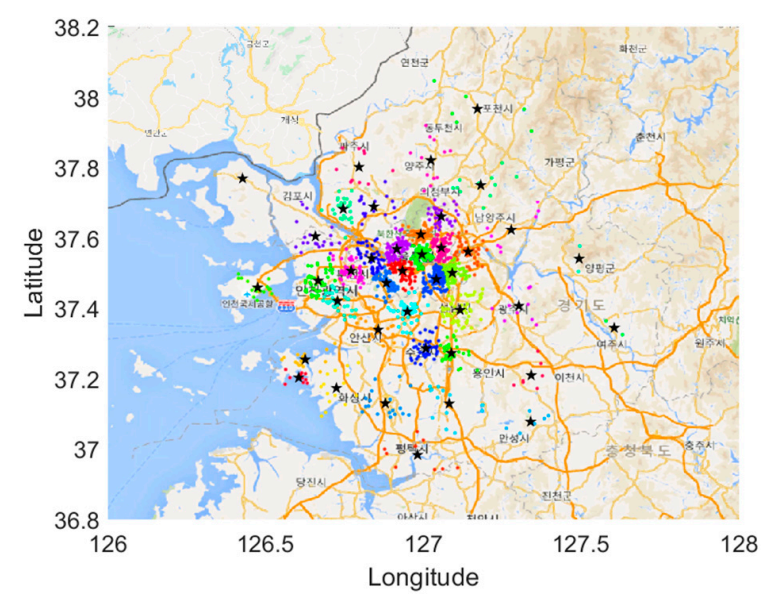

(b)

Figure 9. (a) Result of clustering when the number of vertiports is 10; (b) result of clustering when the number of vertiports is 40 .

According to the reference [19], 100 vertiports are enough for a metropolitan area having 10 million people, such as Seoul. Hence, in this study, we have chosen 100 vertiport locations for optimal vertiports.

\section{Noise Analysis}

\subsection{Aircraft Noise Assessment Methods}

The aircraft noise assessment units vary, and the resulting assessment criteria are all different. Currently, South Korea uses Weighted Equivalent Continuous Perceived Noise Level (WECPNL), as shown in Equation (4). WECPNL is a unit proposed by the International Civil Aviation Organization (ICAO) as a measure of long-term, continuous exposure by aircraft, accounting for the metallic noise characteristics of aircraft. In Korea, noise is calculated close to the actual noise felt by residents by the average of the highest noise of aircrafts weighted by the number of flights per day, night, and in the midnight hours.

$$
W E C P N L=L_{\max }+10 \log \left(N_{2}+3 N_{3}+10\left(N_{1}+N_{4}\right)\right)-27
$$

$L_{\max }$ represents the average of the maximum noise measured for a day over $10 \mathrm{~dB}$ above background noise when the planes pass through. $N_{1}$ represents the number of aircrafts passed between 24:00 and 07:00, $N_{2}$ between 07:00 and 19:00, $N_{3}$ between 19:00 and 22:00, and $N_{4}$ between 22:00 and 24:00.

However, WECPNL tends to be over-approximated, and other environmental noise in the country applies the equivalent noise method $\left(L_{d e n}\right)$, making it difficult to compare with aircraft noise, which is limited to reflecting the sum of continuous noise exposure. In addition, advanced aviation countries, such as the U.S. and Europe, have adopted the equivalent noise method. Therefore, the Ministry of Environment of Korea will change the aircraft noise unit from WECPNL to the equivalent noise method $L_{d e n}$ in order to unify it into an international standard, which is scheduled to take effect in 2023.

The equivalent noise assessment method complements the shortcomings of the $W E C P N L$ and is linearly related to WECPNL. It is also appropriate to use as an aircraft noise assessment indicator considering continuity with the current standard because it is easy to automatically measure with integration without simplification due to the development of noise-measurement technology. 
The equivalent noise assessment method is the average noise divided by $24 \mathrm{~h}$, after measuring the equivalent noise level every hour for a day, and weighted hourly. In addition, the two divisions of the time zone are $L_{d n}$ (day-night average sound level), and the three divisions of the time zone are $L_{d e n}$ (day-evening-night average sound level). In the case of the two divisions, the daytime $L_{d}$ is between 07:00 and 22:00, and the nighttime $L_{n}$ is between 22:00 and 07:00, and only the night time zone is weighted by $10 \mathrm{~dB}$, as shown in Equation (5). In the case of the three divisions, the daytime $L_{d}$ is between 07:00 and 19:00, the evening $L_{e}$ is between 19:00 and 22:00, and the nighttime $L_{n}$ is between 22:00 and 07:00. This case is weighted by $5 \mathrm{~dB}$ in the evening and $10 \mathrm{~dB}$ in the nighttime.

Therefore, in this paper, noise analysis is performed on the basis of $L_{d e n}$, as shown in Equation (6), as the equivalent noise assessment easily measures noise and distinguishes day, evening, and night time zones and will be changed from WECPNL in 2023.

$$
\begin{gathered}
L_{d n}=10 \log \left[\frac{1}{24}\left(15 \cdot 10^{\frac{L_{d}}{10}}+9 \cdot 10^{\frac{\left(L_{n}+10\right)}{10}}\right)\right] \\
L_{d e n}=10 \log \left[\frac{1}{24}\left(12 \cdot 10^{\frac{L_{d}}{10}}+3 \cdot 10^{\frac{L_{e}+5}{10}}+9 \cdot 10^{\frac{L_{n}+10}{10}}\right)\right]
\end{gathered}
$$

\subsection{Determining the Effect of Noise on Population}

\subsubsection{The Formula for Determining the Percentage of Population Affected by Noise}

The operation of eVTOL when UAM is commercialized will result in noise around the operating path, thus affecting the population living in those areas. Therefore, for generating less noise in the UAM operating paths, it is important to measure the percentage of the population in each residential district affected, as shown in Equation (7).

$$
\text { Highly annoyed, } \%=\frac{100}{1+e^{\left(11.13-0.141 L_{d n}\right)}}
$$

Equation (7) is a curve fitting function of the Shultz curve used to calculate the number of residents negatively affected by noise [22]. M. Brink et al. stated that the difference in noise levels between $L_{d n}$ and $L_{d e n}$ in Equations (5) and (6) is small, making it possible to replace $L_{d n}$ in Equation (7) with $L_{d e n}$ [23].

According to the original Shultz curve, high-level noise impact at $65 \mathrm{~dB}$ is about $12 \%$. However, the noise impact of aircraft tends to be higher than other noise sources, and the Miedema curve shows that the noise impact of aircraft is about 27\% [22].

\subsubsection{Determining the Number of People Affected by Noise}

The extent of noise around the route is likely to be limited to parts of the administrative district. In addition, the administrative district is not an ideal shape, such as a square, and residents are not evenly distributed per unit area of the district. Since the current population distribution has statistical data depending on each administrative district, a method to reasonably derive the effect of UAM noise on the population is proposed as follows.

Figure 10a is a hypothetical representation of the noise that eVTOL produces when it passes through an actual city, and Figure $10 \mathrm{~b}$ is modeled in an ideal space of hexagonal tiles.

The actual city of Figure 10 is a replica of Gangseo-gu, with an area of about $41.4 \mathrm{~km}^{2}$. In an ideal city, one hexagon has an area of about $0.8 \mathrm{~km}^{2}$, and the city consists of 52 hexagons. Therefore, the total area of the ideal city is about $41.6 \mathrm{~km}^{2}$, and it is well fitted because it produces about $-0.48 \%$ of the integral error with the actual city.

According to the resident registration demographics serviced by the Ministry of the Interior and Safety of Korea, the total number of residents in Gangseo-gu is 572,377 as of 2021 , and 182,963 of them commute outside Gangseo-gu, according to the Korean Statistical Information Service. In other words, there will be 389,414 people left in Gangseo-gu, and the population is defined as those who can be affected by noise within the living area. On 
the other hand, because the ideal city consists of 52 hexagons, it can be assumed that there are 7489 people per hexagon.

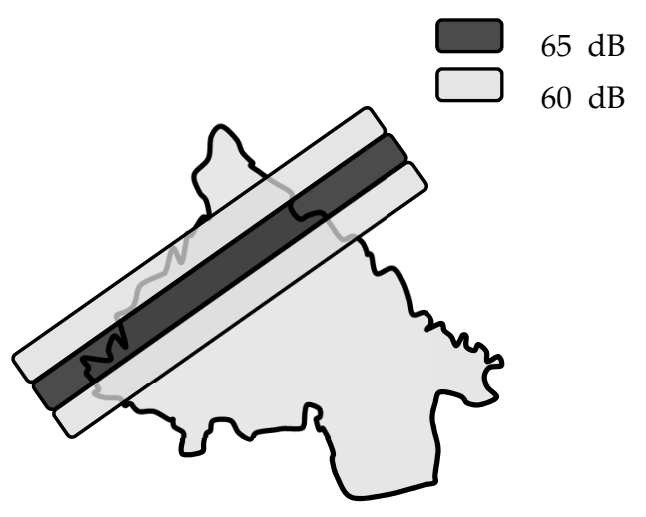

(a)

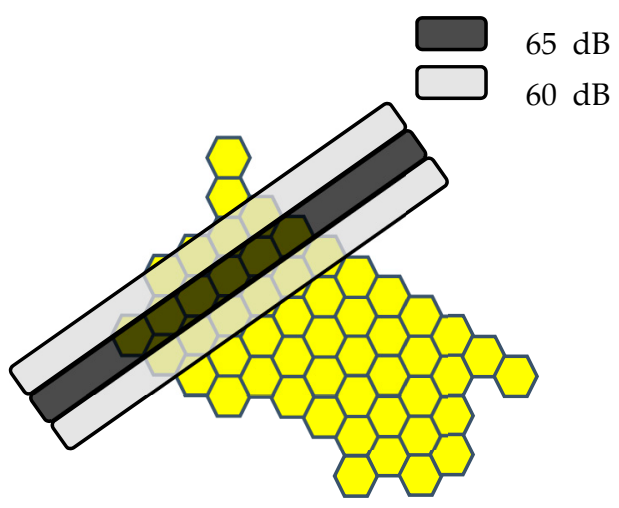

(b)

Figure 10. (a) Virtual noise width of eVTOL passing through the actual city; (b) virtual noise width of eVTOL passing through a virtual city modeled in an ideal space.

At $65 \mathrm{~dB}$ and $60 \mathrm{~dB}$ in the Miedema curve, the effects of air traffic noise are $27 \%$ and $18 \%$ of the total population, respectively. In an ideal city, as shown in Figure 10, $65 \mathrm{~dB}$ contains six hexagons, and $60 \mathrm{~dB}$ contains ten hexagons, and 44,934 and 74,890 represents the number of people living in the hexagons affected by the noise, respectively. As a result, the total number of people affected by the high level of noise generated by the path of the eVTOL vehicle in the ideal city is 12,132 in the $65 \mathrm{~dB}$ section and 13,480 in the $60 \mathrm{~dB}$ section.

In this paper, these methods were applied to analyze the impact of UAM noise on resident populations and present a feasible method for setting up actual UAM noise priority routes.

\subsection{Selection of Routes and Vertiports}

It is assumed that the operation is based on the mission profile, as shown in Figure 11. On AEDT, we assumed that there would be no significant difference in noise analysis by combining vertical take-off, vertical landing, and transitions into one process, so we performed noise analysis assuming these three as one process.

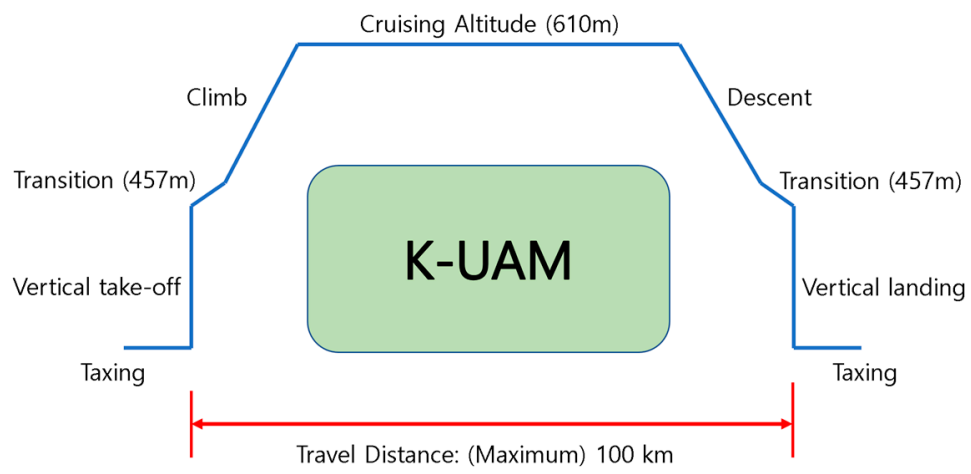

Figure 11. K-UAM mission profile.

A noise priority scenario is a scenario in which most of the paths are set to fly along the least populated area to reduce their impact on noise as much as possible. On the other hand, a business priority scenario is a scenario that heads to a destination at the shortest distance, ignoring the impact of noise. In the case of a single, straight-line business priority 
scenario, it is also necessary to run a step-by-step flight through the node, as is the case with the noise priority scenario in the practice analysis.

The two scenarios are applied to the routes of COEX in Gangnam-gu from Gimpo Airport on the AEDT among the locations of vertiports selected above, as shown in Figure 12. Administrative districts to be included in the districts affected by noise expected from the two routes are Gangseo-gu, Yangcheon-gu, Yeongdeungpo-gu, Dongjak-gu, Seocho-gu, Gangnam-gu, Songpa-gu, Gwanak-gu, Mapo-gu, and Yongsan-gu in Seoul, and Gwacheonsi and Seongnam-si in Gyeonggi-do. Thus, reconstructing each administrative district in the same way as Figure 10 is shown in Figure 13, and Table 7 represents the characteristics of the reconstructed virtual space. Table 7 shows that the average error rate of the actual area and the virtual space area in each zone is $1.1 \%$, and the maximum error rate is $2.7 \%$ of Gwanak-gu; thus, it is situated well.
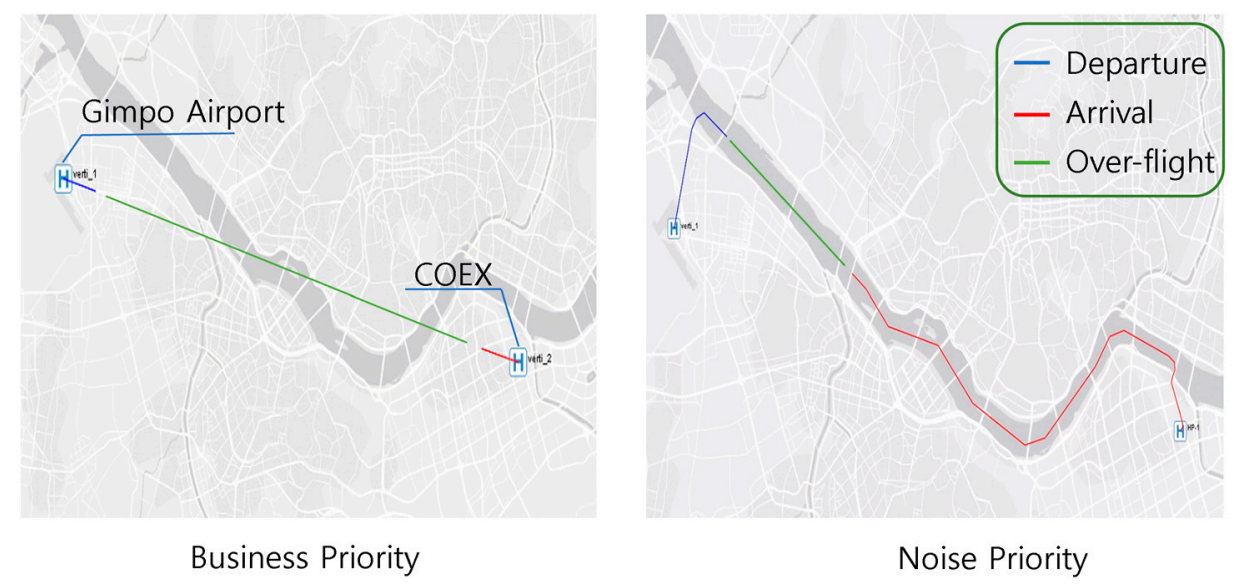

Figure 12. Two methods of route generation from Gimpo airport to COEX.

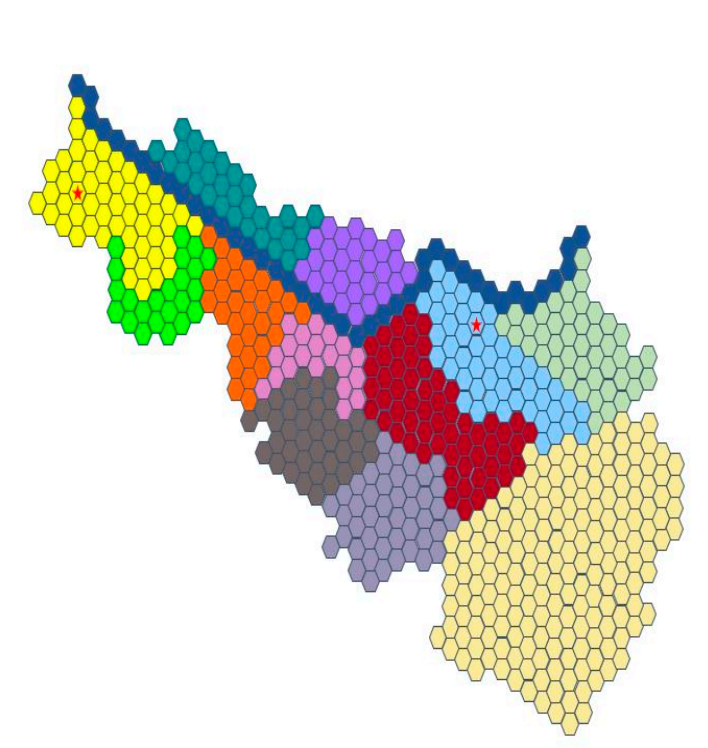

$\checkmark$ Gangseo district

- Yangcheon district

Yeongdeungpo district

Dongjak district

- Gwanak district

- Seocho district

- Gangnam district

Songpa district

- Mapo district

- Yongsan district

Seongnam city

- Gwacheon city

- Han river

Figure 13. Each city and district modeled in the ideal space.

\subsection{Selection of Operating Models}

When eVTOL is commercialized, it will operate simultaneously, and the noise may be a superimposed form of noise from multiple vehicles operating together. Therefore, it is considered desirable to obtain noise by inputting the vehicles into the AEDT software so that it is repeatedly operated. However, the eVTOL developer did not provide the 
data, so in this paper, helicopters, which are currently in operation, were selected as noise operation models.

The helicopters operating for civilian use and market demand in the United States [13] presented in the 2015 FAA Civil Aircraft Registry Database are as shown in Table 8. For this study, analysis was conducted using only a 3-5 seat helicopter type to match the SA-1, a five-seat eVTOL under development by Hyundai Motors.

Table 7. Characteristics of virtual space.

\begin{tabular}{|c|c|c|c|c|c|c|}
\hline & Gangseo-gu & Yangcheon-gu & Yeongdeungpo-gu & Dongjak-gu & Gwanak-gu & Seocho-gu \\
\hline Real area $\left(\mathrm{km}^{2}\right)$ & 41.4 & 17.4 & 24.6 & 16.4 & 29.6 & 47.1 \\
\hline Number of cells & 52 & 22 & 31 & 20 & 38 & 59 \\
\hline Cell area $\left(\mathrm{km}^{2}\right)$ & & & 0.8 & & & \\
\hline Total cells area $\left(\mathrm{km}^{2}\right)$ & 41.6 & 17.6 & 24.8 & 16 & 30.4 & 47.2 \\
\hline \multirow[t]{2}{*}{ Error (\%) } & -0.48 & -1.1 & -0.8 & 2.4 & -2.7 & -0.2 \\
\hline & Gangnam-gu & Songpa-gu & Mapo-gu & Yongsan-gu & Seongnam-si & Gwacheon-si \\
\hline Real area $\left(\mathrm{km}^{2}\right)$ & 39.6 & 33.9 & 23.9 & 21.9 & 141.7 & 35.9 \\
\hline Number of cells & 49 & 43 & 30 & 28 & 177 & 45 \\
\hline Cell area $\left(\mathrm{km}^{2}\right)$ & 0.8 & & & & & \\
\hline Total cells area $\left(\mathrm{km}^{2}\right)$ & 39.2 & 34.4 & 24 & 22.4 & 141.6 & 36 \\
\hline Error (\%) & 1.01 & -1.47 & -0.4 & -2.3 & 0.1 & -0.3 \\
\hline
\end{tabular}

Table 8. Fleet composition of helicopters by type.

\begin{tabular}{|c|c|c|c|}
\hline Helicopter Type & Representative Helicopter & Number of Operations & Proportion (\%) \\
\hline $1-2$ seats piston & Robinson R22 & 1165 & 19.95 \\
\hline $3-5$ seats piston & Robinson R44 & 1160 & 23.29 \\
\hline 6-8 seats turbo-shaft & Bell 206B & 3001 & 51.39 \\
\hline 9-12 seats turbo-shaft & Sikorsky S-76 & 314 & 5.38 \\
\hline \multicolumn{2}{|c|}{ Total } & 5840 & 100 \\
\hline
\end{tabular}

Meanwhile, the target noise of many eVTOL manufacturers is 62 to $63 \mathrm{~dB}$. Therefore, the number of operations was adjusted after fixing it at 06:00-20:00, which includes commuting time, to implement the target noise on the AEDT. The noise map was constructed by increasing the number of operations by 100 from 200 to 500 , and there was no significant difference in the take-off and landing sections; however, in the cruise section, 300-500 helicopters included $65 \mathrm{~dB}-70 \mathrm{~dB}$ noise, and 200 helicopters included $60 \mathrm{~dB}-65 \mathrm{~dB}$, which is the main noise level. Therefore, the number of R44 operations in the AEDT was designated as 200, and the target noise was adjusted to $60-65 \mathrm{~dB}$ on cruise.

\subsection{Noise Analysis}

\subsubsection{Measurement of Noise around the Path Using AEDT}

The noise maps for the two scenarios shown in the AEDT software are the same as Figure 14. In order to perform noise analysis according to the route, eVTOL operating hours were set at 06:00 to 20:00, including rush hour, and noise analysis was conducted by applying R44, a five-seat helicopter, for that time.

In the AEDT software, the grid method was selected for the receptor setting, for which the noise map is configured in the range. Since the path is from west to east, a total of 10,000 receptors were placed on the path: 100 from the $X$-axis and 100 from the $Y$-axis, based on latitude 37.48 and longitude 126.64. The interval between receptors was set to 0.31 nautical miles for the $X$-axis and 0.1 nautical miles for the $Y$-axis. 
According to the FAA, $60 \mathrm{~dB}$ is the typical noise at the urban level, over $65 \mathrm{~dB}$ is the noise outside the critical noise-exposure level, and $55 \mathrm{~dB}$ is the quiet noise at the suburban level. Therefore, since this paper aims to analyze noise for eVTOL to operate in urban areas, noise below $55 \mathrm{~dB}$ was been considered. In addition, the analysis excludes receptors arising from out-of-path sections where the department line and arrival line are not exactly in line when a path is made via AEDT.

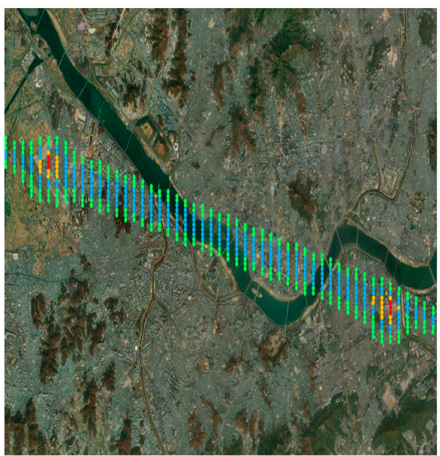

Business Priority

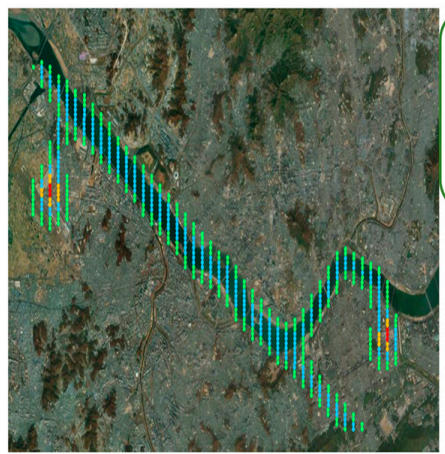

Noise Priority

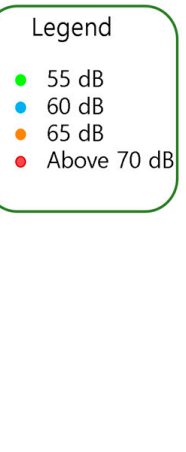

Figure 14. Noise maps for two different scenarios.

\subsubsection{Predicting the Effect of Measured Noise on Population}

To determine the number of people affected by noise, population data distributed in each hexagon were obtained. The population data were assumed by the number of people living in each administrative district minus the number of people moving to another administrative district for commuting at working time. Table 9 represents the distribution of the number of residents in each hexagon based on population data provided by the Ministry of the Interior and Safety and Statistics Korea.

Table 9. Residents in each hexagon of metro county.

\begin{tabular}{ccccc}
\hline Region & Total Population & $\begin{array}{c}\text { Moving } \\
\text { Population }\end{array}$ & Living Population & $\begin{array}{c}\text { Population on } \\
\text { Each Cell }\end{array}$ \\
\hline Gangseo-gu & 572,377 & 182,963 & 389,414 & 7489 \\
\hline Yangcheon-gu & 449,208 & 161,693 & 287,512 & 13,069 \\
\hline Yeongdeungpo-gu & 373,285 & 118,455 & 254,830 & 8220 \\
\hline Dongjak-gu & 384,076 & 145,204 & 238,872 & 11,944 \\
\hline Gwanak-gu & 485,826 & 182,685 & 303,141 & 7977 \\
\hline Seocho-gu & 415,629 & 135,668 & 279,961 & 4745 \\
\hline Gangnam-gu & 526,046 & 148,672 & 377,374 & 7702 \\
\hline Songpa-gu & 656,548 & 195,736 & 460,812 & 10,717 \\
\hline Mapo-gu & 363,789 & 123,102 & 240,687 & 8023 \\
\hline Yongsan-gu & 220,239 & 68,852 & 151,387 & 5407 \\
\hline Seongnam-si & 927,886 & 236,255 & 691,661 & 3908 \\
\hline Gwacheon-si & 66,420 & 24,530 & 41,890 & 931 \\
\hline
\end{tabular}

Figure 15 shows the overlapped image of the noise map obtained through AEDT and the administrative districts in the Seoul metropolitan area composed of hexagons. Table 10 represents the number of hexagons through which receptors pass each administrative district from the results in Figure 15. The results above $65 \mathrm{~dB}$ are the same for both paths since both occur on vertical take-off and landing. In other words, the effect of noise depends on the cruise section in which $60 \mathrm{~dB}$ receptors are distributed. Therefore, from the results in Table 10, the population residing in the $60 \mathrm{~dB}$ to $65 \mathrm{~dB}$ range was multiplied by the 
noise-exposure ratio in the Miedema curve [22], and the number of people affected by high levels of noise in each scenario is shown in Table 11.

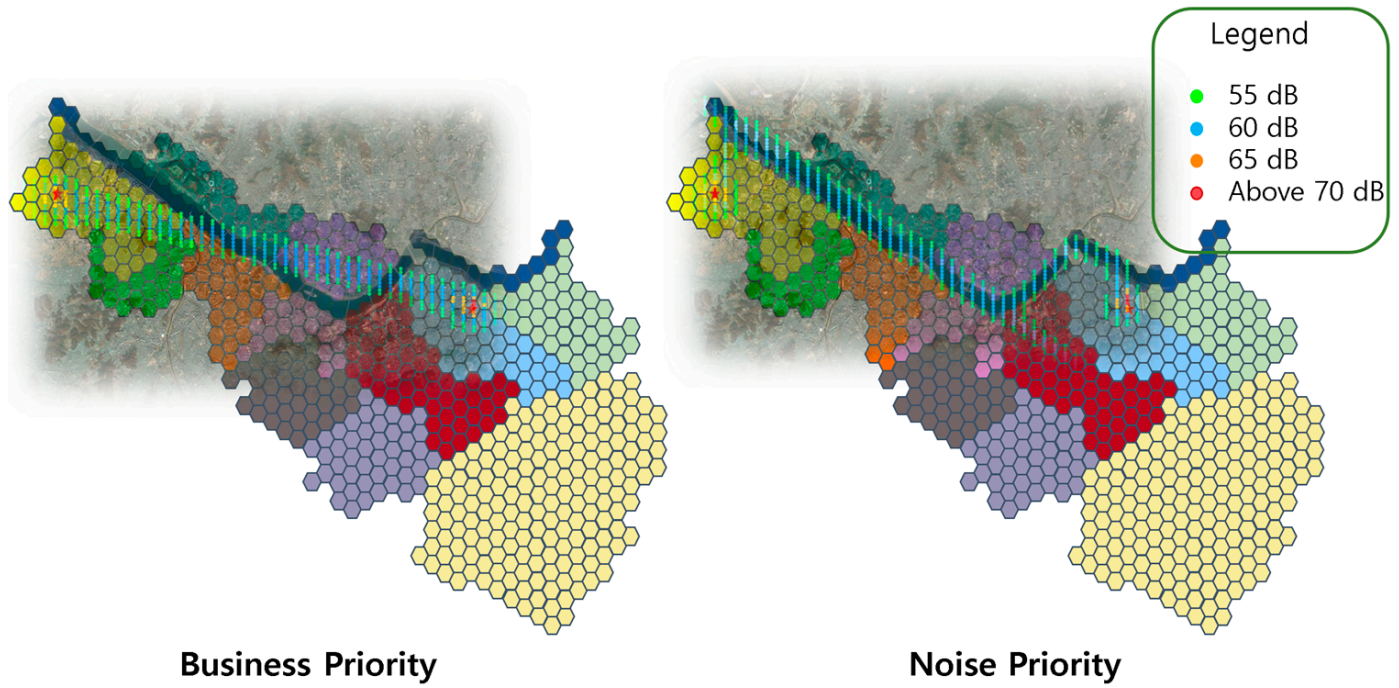

Figure 15. Noise analysis results for two different scenarios in the modeled area.

Table 10. The number of hexagons per administrative district passing the noise area for two scenarios.

\begin{tabular}{|c|c|c|c|c|c|c|}
\hline \multirow[b]{2}{*}{ Region } & \multicolumn{3}{|c|}{ Business Priority } & \multicolumn{3}{|c|}{ Noise Priority } \\
\hline & $60 \mathrm{~dB}$ & $65 \mathrm{~dB}$ & Above70 dB & $60 \mathrm{~dB}$ & $65 \mathrm{~dB}$ & Above $70 \mathrm{~dB}$ \\
\hline Gangseo-gu & 11 & 3 & 1 & 5 & 3 & 1 \\
\hline Yangcheon-gu & 2 & - & & - & - & - \\
\hline Yeongdeungpo-gu & 3 & - & & - & - & - \\
\hline Dongjak-gu & - & - & & - & - & - \\
\hline Gwanak-gu & - & - & & - & - & - \\
\hline Seocho-gu & - & - & & 1 & - & - \\
\hline Gangnam-gu & 6 & 4 & 1 & 2 & 4 & 1 \\
\hline Songpa-gu & - & - & & - & - & - \\
\hline Mapo-gu & 2 & - & & - & - & - \\
\hline Yongsan-gu & 10 & - & & - & - & - \\
\hline Seongnam-si & - & - & & - & - & - \\
\hline Gwacheon-si & - & - & & - & - & - \\
\hline
\end{tabular}

Table 11. Size of population exposed to high levels of noise by scenarios.

\begin{tabular}{ccc}
\hline Scenario & Business Priority Scenario & Noise Priority Scenario \\
\hline \multicolumn{3}{c}{ Population } \\
\hline \multicolumn{3}{c}{ Highly annoyed (\%) } \\
\hline \multicolumn{3}{c}{18} \\
\hline Population of noise exposure \\
\hline $60 \mathrm{~dB}$ & \multicolumn{2}{c}{18,594} \\
\hline
\end{tabular}

As a result, the number of people affected by noise decreased by about $76.9 \%$ in a noise priority scenario compared to in a business priority scenario. 


\section{Results}

In this paper, the locations of vertiports, which is the infrastructure necessary to apply urban air mobility (UAM), which has not yet been commercialized in the Seoul metropolitan area, were selected and evaluated, and AEDT software was used to establish UAM routes. A noise priority scenario was then applied based on population distribution.

To accomplish this, data from the Statistics Korea's commuting population survey by residents/commuters were collected, and MATLAB was used to show it on the map. The data were clustered using the K-means algorithm to obtain 40 and 100 locations suitable for vertiports. However, if it is impossible to install a vertiport due to mountain, sea, or residential areas, the repositioning process was deemed necessary, and through this process, the final vertiport was selected. While performing the repositioning process in the Seoul metropolitan area, it was difficult to select the locations of the vertiports because most areas are residential areas. However, the locations of the vertiports were selected by utilizing such areas as Han River Park, Highway IC, and the rooftop of the parking lot building suggested by Uber. It was also determined that a helipad, located on the rooftop of a skyscraper, could serve as a vertiport. In addition, the noise priority scenario shows a $76.9 \%$ decrease in the number of people affected by high levels of noise compared to the business priority scenario, which is a simple straight path. In Korea, mountainous areas, airports, and military facilities are concentrated in a narrow land area, so there are many restricted areas for flights; therefore, the development of UAM routes and noise analysis are essential rather than straight lines from the origin to the destination.

The demand data used in this paper are the number of commuters provided by Statistics Korea. This was collected through the census and has excellent accuracy. However, it was difficult to express data in large administrative districts, such as Pocheon-si and Hwaseong-si in Gyeonggi-do, or in an administrative district that is divided into two, such as Ansan-si, because information was only given on the administrative districts and the specific origin and destination locations are unknown. However, since a satellite map was used to select the origin and destination of the most likely candidate sites for the location repositioning process, it is expected to be highly utilized as a final vertiport. For this study, the locations of the vertiports were selected using only the number of commuters, but if UAM is commercialized, it is believed that moving for leisure and tourism will also account for a large portion. Therefore, it is necessary to analyze mobility with various purposes and select the locations of the vertiports.

Considering the lack of data provided by eVTOL developers, the noise analysis process used helicopters as models and was conducted by distributing residents evenly by administrative districts without using more precise data about the residential area. Therefore, it is believed that a better result would be achieved if the path is created using real eVTOL noise data and more detailed population data, applying the exact area affected by real noise using spatial information rather than just the number of hexagons containing receptors. In addition, noise analysis due to changes in operating altitude and payload is required.

On the other hand, for UAM to operate across all administrative districts, noise priority routes must be considered where there is no terrain to reduce noise, such as rivers. For example, for two noise priority scenarios, the scenario that passes through administrative districts with a larger population distribution per hexagon than the other will result in an increase in the population exposed to noise, which will have minimal effect on reducing noise impact.

Therefore, it is necessary to build an optimized path by analyzing the factors affecting various noise priority scenarios, and these studies are believed to contribute to the early commercialization of UAM.

Author Contributions: Conceptualization, J.J. and M.S.; methodology, J.J. and M.S.; software, J.J. and M.S.; validation, H.-Y.H.; formal analysis, J.J.; investigation, J.J.; resources, H.-Y.H.; data curation, J.J.; writing—original draft preparation, J.J. and M.S.; writing—review and editing, H.-Y.H.; visualization, 
J.J. and M.S.; supervision, H.-Y.H.; project administration, H.-Y.H.; funding acquisition, H.-Y.H. All authors have read and agreed to the published version of the manuscript.

Funding: This work is supported by the Korea Agency for Infrastructure Technology Advancement (KAIA) grant funded by the Ministry of Land, Infrastructure and Transport (Grant 21CTAP-C157731-02).

Institutional Review Board Statement: Not applicable.

Informed Consent Statement: Not applicable.

Data Availability Statement: All data are available in the public.

Conflicts of Interest: The authors declare no conflict of interest.

\section{References}

1. Citypopulation. Available online: https://www.citypopulation.de/en/southkorea/admin/ (accessed on 30 April 2021).

2. Park, J.; The Korea Transport Institute, Sejong, Korea; Kim, G.J.; The Korea Transport Institute, Sejong, Korea; Lee, S.; The Korea Transport Institute, Sejong, Korea. Improvement Plan for Resolving Capital Area Metropolitan Transportation Issues. Personal communication, 2019.

3. Uber. Available online: https://www.uber.com/elevate.pdf (accessed on 30 April 2021).

4. NASA. Available online: https://www.nasa.gov/aam-studies-reports/ (accessed on 30 April 2021).

5. Antcliff, K.R.; Moore, M.D.; Goodrich, K.H. Silicon Valley as an Early Adopter for On-Demand Civil VTOL Operations. In Proceedings of the 16th AIAA Aviation Technology, Integration, and Operations Conference, Washington, DC, USA, 13-17 June 2016.

6. CORGAN. Available online: https://www.corgan.com/wp-content/uploads/2019/06/20190612_UberBook_Spreads_ REDUCED-FOR-WEB.pdf (accessed on 30 April 2021).

7. Daskilewicz, M.J.; German, B.J.; Warren, M.M.; Garrow, L.A.; Boddupalli, S.-S.; Douthat, T.H. Progress in Vertiport Placement and Estimating Aircraft Range Requirements for eVTOL Daily Commuting. In Proceedings of the 2018 Aviation Technology, Integration, and Operations Conference, Atlanta, GA, USA, 25-29 June 2018.

8. German, B.J.; Daskilewicz, M.J.; Hamilton, T.K.; Warren, M.M. Cargo Delivery by Passenger eVTOL Aircraft: A Case Study in the San Francisco Bay Area. In Proceedings of the 2018 AIAA Aerospace Sciences Meeting, Kissimmee, FL, USA, 8-12 January 2018.

9. Rajendran, S.; Zack, J. Insights on strategic air taxi network infrastructure locations using an iterative constrained clustering approach. Transp. Res. Part E Logist. Transp. Rev. 2019, 128, 470-505. [CrossRef]

10. Ploetner, K.O.; Al Haddad, C.; Antoniou, C.; Frank, F.; Fu, M.; Kabel, S.; Llorca, C.; Moeckel, R.; Moreno, A.T.; Pukhova, A.; et al. Long-term application potential of urban air mobility complementing public transport: An upper Bavaria example. CEAS Aeronaut. J. 2020, 11, 991-1007. [CrossRef] [PubMed]

11. Syed, N.; Rye, M.; Ade, M.; Trani, A.; Hinze, N.; Swingle, H.; Smith, J.; Marien, T.; Dollyhigh, S. Preliminary Considerations for ODM Air Traffic Management based on Analysis of Commuter Passenger Demand and Travel Patterns for the Silicon Valley Region of California. In Proceedings of the 17th AIAA Aviation Technology, Integration, and Operations Conference, Denver, CO, USA, 5-9 June 2017.

12. Lim, E.; Hwang, H. The Selection of Vertiport Location for On-demand Mobility and Its Application to Seoul Metro Area. Int. J. Aeronaut. Space Sci. 2019, 20, 260-272. [CrossRef]

13. Kim, J.H.; Lim, D.; Min, S.; Mavris, D. Prediction of Community Noise Impacts from Commercialization of Vertical Takeoff and Landing Personal Air Vehicles. In Proceedings of the 16th AIAA Aviation Technology, Integration, and Operations Conference, Washington, DC, USA, 13-17 June 2016.

14. Uber Air Vehicle Requirements and Missions. Available online: https://s3.amazonaws.com/uber-static/elevate/Summary+ Mission+and+Requirements.pdf (accessed on 30 April 2021)

15. Statistics Korea. Available online: http://kostat.go.kr/portal/eng/index.action (accessed on 30 April 2021).

16. MATLAB R2020b. 2020. Available online: https://kr.mathworks.com/?s_tid=gn_logo (accessed on 30 April 2021).

17. Manning, C.D.; Raghavan, P.; Schütze, H. An Introduction to information Retrieval, online ed.; Cambridge University Press: Cambridge, UK, 2009; pp. 360-368.

18. Mardia, K.V.; Kent, J.T.; Bibby, J.M. Multivariate Analysis, 1st ed.; Academic Press: San Diego, CA, USA, 1980 ; pp. $360-393$.

19. Porsche Consulting. Available online: https://www.porsche-consulting.com/en/press/insights/detail/study-the-future-ofvertical-mobility/ (accessed on 30 April 2021).

20. Rousseeuw, P.J. Silhouettes: A graphical aid to the interpretation and validation of cluster analysis. J. Comput. Appl. Math. 1987, 20,53-65. [CrossRef]

21. Open Platform. Available online: https://map.vworld.kr/map/maps.do (accessed on 30 April 2021).

22. Civil Aviation Authority. Available online: http:// publicapps.caa.co.uk/modalapplication.aspx?appid=11\&catid=1\&id=8246 \&mode $=$ detail\&pagetype $=65$ (accessed on 30 April 2021)

23. Brink, M.; Schäffer, B.; Pieren, R.; Wunderli, J.M. Conversion between noise exposure indicators Leq ${ }_{24 h}, L_{\text {Day }}, L_{E v e n i n g}, L_{N i g h t}, L_{d n}$ : Principles and practical guidance. Int. J. Hyg. Environ. Health 2018, 211, 54-63. 